\title{
PENERAPAN TEKNIK OMBRE DIPADU CAT EYES TERHADAP HASIL KOREKSI MATA SIPIT UNTUK RIAS WAJAH MALAM HARI
}

\author{
Atika Diana ${ }^{1}$, Hayatunnufus ${ }^{2}$ \\ 1Program Studi Pendidikan Tata Rias dan Kecantika \\ 2 Fakultas Pariwisata dan Perhotelan Universitas Negeri Padang \\ Email : dianaatika.21@gmail.com
}

\begin{abstract}
This research aims to analyze the effect of the application of ombre technique combined with cat eyes on the slanted eyes shape correction in night makeup that is assessed based on indicator of the impression of the length of the eye, the impression of the width of the eye and folds of the eyelids. This research is a quantitative research with quasi experimental method with Non equevalent control group design. The object in this study were three samples with slanted eyes characteristics. Sampling using purposive sampling technique. Based on the data analysis, it was found that: a) The control group without using scote tape and fake eyelashes showed less optimal results, b) The experimental group using scote tape and false eyelashes showed very maximum results, c)The hypothesis that reads "there is a significant influence on the application of the Ombre technique combined with cat eyes on the results of slanted eyes correction for night makeup" was accepted at 95\% significance level because the price of t count> t table $(7,721>$ $1,895)$.
\end{abstract}

Keywords : Ombre, cat eyes, slanted eyes, and night makeup

\section{PENDAHULUAN}

Tujuan dari merias wajah adalah mempercantik diri sehingga membangkitkan rasa percaya diri (Tilaar, 2009:9) . Pada dasarnya merias diri juga harus disesuaikan dengan waktu dan kesempatan.Pada dasarnya merias diri juga harus disesuaikan dengan waktu dan kesempatan. Menurut Rahmiati dkk (2013:171) "ada tiga macam dari tata rias yaitu yang pertama rias wajah pagi hari, kedua rias wajah sore, dan ketiga rias wajah malam hari".

Salah satunya yang menjadi pusat perhatian yaitu rias wajah malam yang di nyatakan oleh Rahmiati, dkk (2013:177) bahwa : "Rias wajah malam hari adalah rias wajah yang menggunakan alas bedak (cream foundation), dan menggunakan perona mata yang lebih mencolok dengan menggunakan bulu mata palsu. Untuk rias malam hari, gunakan riasan perona mata yang mengandung shimmer dan mengkilap, serta seusaikan warna riasan dengan kesempatan. Apabila untuk kesempatan pesta dapat digunakan riasan yang lebih mencolok dan glamour".Salah satu yang menjadi pusat perhatian dalam riasan adalah mata. Bentuk mata yang dimiliki setiap manusia pada dasarnya beragam dan berbedabeda.

Berdasarkan ciri-ciri mata ideal yang dikemukakan di atas bahwa bentuk mata yang tidak memiliki ciri-ciri atau kurang mendekati mata ideal berarti harus di koreksi untuk menyempurnakan bentuk mata. Menurut Gusnaldi (2008:54) "bentuk mata di bagi menjadi 5 macam, diantaranya 1 . Bentuk mata bulat, 2. Bentuk sipit, 3. Bentuk mata dalam, 4. Bentuk mata turun, 5. Mata kecil". Dari berbagai bentuk mata yang ada, Salah satu bentuk mata yang kurang ideal dan membutuhkan koreksi adalah bentuk mata sipit. Menurut Permadi (2014:15) "jenis mata sipit, tidak memiliki lipatan sama sekali pada 
permukaan kelopak dan tulang alis tidak menonjol".Dengan demikian diperlukan beberapa teknik pengoreksian untuk menunjang kesan mata mendekati ideal. Gusnaldi (2004:32) menjelaskan bahwa"Pada umumnya, pengoreksian mata dilakukan menggunakan scote tape dan bulu mata palsu".

Mata tak akan lengkap kehadirannya tanpa helaian bulu mata yang melentik cantik. Sebab, bulu mata bisa membantu membuat mata terlihat segar, indah dan bercahaya (Gusnaldi 2010:25). Keindahan mata lebih sempurna dengan bulu mata. Rahmiati dkk (2013:146) menyatakan bahwa "bulu mata palsu berguna agar bulu mata terkesan tebal dan membuat mata lebih ekspresif". Dengan demikian bulu mata sangat di perlukan untuk membuat mata lebih sempurna. Untuk itu diperlukan bulu mata yang sesuai dengan jenis mata sipit. Andiyanto (2013:64) menyatakan bahwa "bulu mata palsu yang panjang dan rapat adalah jenis bulu mata yang dapat digunakan untuk membuat kesan mata lebih besar". Kemudian di perkuat oleh Gusnaldi (2009:82) bahwa " bulu mata panjang dan rapat adalah jenis bulu mata yang cocok digunakan untuk mata sipit tak berkelopak".

Teknik yang dilakukan pada penelitian ini adalah teknik ombre dipadu cat eyes. Ovyntarima (2016) menyatakan bahwa "istilah ombre adalah bayangan atau gradasi warna yang membayang dari gelap menuju kearah semakin terang secara bertingkat". Pada penggunaan teknik ombre Kusumawardhani dan Sugimurwati (2014:23) menjelaskan sebagai berikut: Untuk memadukan kedua warna, sebaiknya dalam satu harmoni warna.

Teknik cat eyes adalah penekanan pada sudut luar mata agar terkesan menjadi lebih tinggi atau naik menyerupai mata kucing. Untuk memperoleh tarikan eyeliner yang sempurna. serta teknik dan pengaplikasian cat eyes dengan teknik tarikan eyeliner yang membuat mata terkesan besar dengan menggunakan eyeliner cair. Pada dasarnya riasan yang menggunakan teknik cat eyes cocok diterapkan untuk mata apa saja (Gusnaldi, 2010:51).

Berdasarkan hasil wawancara yang penulis lakukan pada mahasiswi Jurusan Tata Rias dan Kecantikan tahun masuk 2014 yang diwawancarai 10 orang dari 30 orang mahasiswi pada bulan
Agustus 2018 yang terjun langsung ke lapangan freelance sebagai make up artist bahwa mahasiswi sering kali mendapat kesulitan pada saat merias mata sipit sehingga jarang menggunakan scote tape serta membuat pekerjaan menjadi lama dan kurang efisien. Dan juga mahasiswi belum paham dengan melakukan teknik ombre dipadu cat eyes pada mata sipit. Pada dasarnya teknik ombre dipadu cat eyes itu merupakan teknik gradasi warna yang sering di gunakan.

Berdasarkan hasil wawancara pada tanggal 4 September 2018 pada salon Twinz Couture penulis langsung mewawancarai owner Cardo Ricky berpendapat bahwa teknik ombre dipadu cat eyes merupakan teknik gradasi warna yang biasa digunakan dalam meris wajah, yaitu dengan perpaduan warna eyeshadow yang akan digunakan. Jenis scote tape yang biasa digunakan yaitu scote tape yang berjenis kertas karena lebih gampang menyerap warna eyeshadow. Sesuai dengan pernyataan Andiyanto (2013:24) bahwa "Scotch tape terbuat dari kertas berwarna cream. Kelebihan dari scote tape ini adalah terlihat natural dan menyerap warna eyeshadow secara maksimal". Sedangkan, Teknik cat eyes yaitu pemasangan eyeliner yang pada sudut mata membentuk segitiga dan agak tebal pada bagian sudut mata sehingga dapat membantu mata sipit menjadi lebih besar. Cardo berpendapat bahwa teknik ombre dipadu cat eyes sangat cocok digunakan pada mata sipit untuk rias malam hari.

\section{METODE}

Penelitian ini adalah penelitian kuantitatif dengan metode eksperimen semu (quasi eksperiment) dengan desain Non eque valent control group design.

\section{Rancangan penelitian}

Penelitian ini dijalankan dengan metode experiment dengan melakukan penerapan teknik ombre dipadu cat eyes terhadap koreksi mata sipit untuk rias wajah malam hari.

\section{Populasi dan sampel penelitian}

Pada penelitian ini, populasi yang dimaksudkan adalah seluruh mahasiswa jurusan Tata Rias dan Kecantikan angkatan 2014 yang terdaftar pada kelas berjumlah 30 orang mahasiswi Objek dalam penelitian ini adalah tiga orang sampel memiliki ciri-ciri mata sipit dengan perlakuan yang berbeda. Pengambilan sampel menggunakan teknik purposive sampling.

\section{Prosedur penelitian}


Prosedur dalam penelitian ini dilakukan untuk mengetahui perbandingan teknik ombre dipadu cat eyes terhadap hasil koreksi mata sipit untuk rias wajah malam hari dengan beberapa tahap yaitu : tahap persiapan, tahap perlakuan, tahap setelah perlakuan yang akan dijelaskan sebagai berikut:

\section{Tahap Persiapan}

mempersiapkan alat dan bahan yang digunakan

a. Persiapan alat yang digunakan

1) Kuas set

2) Spons foundation

3) Penjepit bulu mata

b.Persiapan Bahan yang digunakan

1) Kapas

2) Cotton buds

3) Scote tape bahan kertas

4) Bulu mata palsu

c. Persiapan kosmetik yang digunakan
1) Milk cleanser
2) Toner
3) Foundation
4) Bedak tabur
5) Bedak padat
6) Pensil alis
7) Eyeshadow
8) Eyeliner liquid
9) Eyeliner pensil
10) Maskara
11) Lem bulu mata palsu
12) Blush on
13) Lipstik

\section{Tahap perlakuan}

Sebelum melakukan rias malam, wajah dibersihkan terlebih dahulu menggunakan milk cleanser menggunakan teknik lima pokok pembersihan dan dilanjutkan menggunakan toner.

a. Tahapan pertama

Tahapan awal yang dilakukan peneliti adalah melakukan proses rias malam dengan penerapan teknik ombre dipadu cat eyes tanpa menggunakan scote tape dan bulu mata Palsu terhadap mata sipit. Kemudian hasil pengaplikasian koreksi mata tahap awal ini dilakukan penilaian oleh panelis sebagai hasil penelitian terhadap variabel X1 sesuai dengan indikator penelitian.

b. Tahap kedua
Tahapan kedua dari prosedur peneilitian ini adalah menghapus makeup pada bagian mata lalu di lakukan pengkoreksian terlebih dahulu menggunakan scote tape lalu menerapkan teknik ombre dipadu cat eyes menggunakan scote tape.dan bulu mata palsu terhadap mata sipit. Kemudian hasil pengaplikasian koreksi mata tahap kedua ini dilakukan penilaian oleh panelis sebagai hasil penelitian terhadap variabel X2 sesuai dengan indikator penelitian

c. Tahap ketiga

Tahapan ketiga dari prosedur peneilitian ini adalah perlakuan terakhir adalah pengaplikasian rias wajah secara keseluruhan terhadap 3 (tiga) orang objek dan tahap terakhir yang dinilai oleh panelis dengan melihat hasil perbandingan eksperimen 1 dan eksperimen 2 yang telah di dokumentasi.

\section{Tahap setelah perlakuan}

Tahap yang dilakukan setelah perlakuan adalah

a. Setelah perlakuan dengan teknik ombre dipadu cat eyes diamati untuk mengukur dari indikator dan mengisi lembaran penilaian yang telah dibuat berdasarkan kartegori yang telah ditetapkan untuk setiap indikator.

b. Membandingkan penerapan teknik ombre dipadu cat eyes terhadap hasil koreksi mata sipit dengan penggunaan scote tape, dan bulu mata palsu untuk rias malam.

\section{Teknik pengumpulan data dan pengembangan} instrumen

1. Teknik Pengumpulan Data

Teknik pengumpulan Data yang digunakan adalah:

a. Observasi

Berdasarkan pengamantan yang penulis lakukan dalam proses rias wajah malam dengan penerapan teknik ombre dipadu cat eyes terhadap hasil koreksi mata sipit maka penulis dapat melihat langsung hasil perbandingan dari penerapan teknik ombre dipadu cat eyes tanpa scote tape dan bulu mata palsu sehingga penulis dapat menerapkan dalam teknik rias yang baru dari hasil penelitian ini. 


\section{c. Dokumetasi}

Dokumentasi ini bermanfaat untuk menyajikan gambaran hasil dari penelitian dalam bentuk foto/gambar, guna memberikan informasi yang berkaitan dengan penerapan teknik ombre dipadu cat eyes terhadap hasil koreksi mata sipit untuk rias malam.

2. Instrumentasi penelitian

Instrumen merupakan alat yang digunakan untuk mendapatkan data. Instrumen dalam penelitian ini berbentuk panduan pengamatan perbedaan hasil penerapan teknik ombre dipadu cat eyes terhadap hasil koreksi mata sipit untuk rias malam.Penyusunan instrumen dilakukan dengan beberapa langkah sebagai berikut:

a. Penentuan indikator

Penentuan indikator pada variabel dengan melihat perubahan hasil yang terjadi yaitu pengaruh penerapan teknik ombre dipadu cat eyes terhadap hasil koreksi mata sipit untuk rias malam.

b. Penyusunan skor indikator

Pada penelitian ini data hasil penilaian dari data hasil pengamatan secara visual terdapat hasil koreksi bentuk mata sipit, berupa nilai berbentuk kuantitatif pada penelitian agar data hasil penelitian ini bisa dianalisis secara

\begin{tabular}{|c|c|c|c|}
\hline Indikator & Sampel 1 & Sampel 2 & Sampel 3 \\
\hline $\begin{array}{l}\text { Kesan } \\
\text { Panjang } \\
\text { Mata }\end{array}$ & $\begin{array}{l}\text { Panjang } \\
\text { mata } \\
\text { sedikit } \\
\text { bertambah }\end{array}$ & $\begin{array}{l}\text { Panjang } \\
\text { mata } \\
\text { sedikit } \\
\text { bertambah }\end{array}$ & $\begin{array}{l}\text { Panjang } \\
\text { mata sedikit } \\
\text { bertambah }\end{array}$ \\
\hline Rata-rata & \multicolumn{3}{|c|}{$2,0=$ Panjang mata sedikit bertambah } \\
\hline $\begin{array}{l}\text { Kesan } \\
\text { Lebar } \\
\text { Mata }\end{array}$ & $\begin{array}{l}\text { Lebar mata } \\
\text { sedikit } \\
\text { bertambah }\end{array}$ & $\begin{array}{l}\text { Lebar } \\
\text { mata } \\
\text { sedikit } \\
\text { bertambah }\end{array}$ & $\begin{array}{l}\text { Lebar mata } \\
\text { sedikit } \\
\text { bertambah }\end{array}$ \\
\hline Rata-rata & \multicolumn{3}{|c|}{$2,0=$ Lebar mata sedikit bertambah } \\
\hline $\begin{array}{l}\text { Lipatan } \\
\text { Kelopak } \\
\text { Mata }\end{array}$ & $\begin{array}{l}\text { Lipatan } \\
\text { kelompak } \\
\text { mata tetap }\end{array}$ & $\begin{array}{l}\text { Lipatan } \\
\text { kelopak } \\
\text { mata sedikit } \\
\text { terlihat }\end{array}$ & $\begin{array}{l}\text { Lipatan } \\
\text { kelopak } \\
\text { mata sedikit } \\
\text { terlihat }\end{array}$ \\
\hline Rata-rata & \multicolumn{3}{|c|}{$\begin{array}{c}1,67 \text { = Lipatan Kelopak Mata sedikit } \\
\text { terlihat }\end{array}$} \\
\hline
\end{tabular}

statistik, maka nilai hasil pengamatan disusun dalam suatu skala penilaian yaitu skala bertingkat (ratting scale). Kategori penilaian dalam penelitian ini diamati dari kesan ukuran panjang mata, kesan ukuran lebar mata, dan lipatan kelopak mata.

\section{Teknik Analisis Data}

Teknik penilaian dengan pengamatan secara organoleptik dengan indera penglihatan dari panelis. Data yang terkumpul dari penelitian berupa data primer yang diperoleh lansung dari panelis dengan mengisi format penilaian yang telah disediakan. Teknik pengumpulan data dilakukan dengan uji normalitas, uji homogenitas dan dilanjutkan dengan analisis uji T.

\section{HASIL DAN PEMBAHASAN}

\section{A. Hasil}

Deskripsi Hasil Pengaplikasian Penerapan teknik ombre dipadu cat eyes terhadap koreksi mata sipit tanpa menggunakan scote tape dan bulu mata palsu untuk rias malam $\left(\mathrm{X}_{1}\right)$.

\section{Tabel 1. Kelompok Kontrol $\left(\mathrm{X}_{1}\right)$}

Dari tabel di atas diperoleh tingkat pencapaian keberhasilan yaitu:

\section{a. Kesan Panjang Mata yang Terlihat}

Penerapan teknik ombre dipadu cat eyes terhadap koreksi mata sipit tanpa menggunakan scote tape dan bulu mata palsu untuk rias malam dilihat dari indikator kesan panjang mata yang terlihat pada sampel 1 dengan skor 2,0 berkategori panjang mata sedikit bertambah, sampel 2 dengan skor 2, berkategori panjang mata sedikit bertambah dan sampel 3 dengan skor 2,0 berkategori panjang mata sedikit bertambah. Skor rata-rata keseluruhan yaitu 2,0 yang berarti kesan panjang mata yang terlihat sedikit bertambah dari bentuk awal.

b. Kesan Lebar Mata yang Terlihat

Penerapan teknik ombre dipadu cat eyes terhadap koreksi mata sipit tanpa menggunakan scote tape dan bulu mata palsu untuk rias malampada dilihat dari indikator kesan lebar mata yang terlihat pada sampel 1 dengan skor 2,0 berkategori lebar mata sedikit bertambah, sampel 2 dengan skor 2, berkategori lebar mata sedikit bertambah dan sampel 3 dengan skor 2,0 berkategori lebar mata sedikit bertambah. Skor rata-rata keseluruhan yaitu 2,0 yang berarti kesan lebar mata yang terlihat sedikit bertambah dari bentuk awal.

\section{c. Lipatan Kelopak Mata}


Penerapan teknik ombre dipadu cat eyes terhadap koreksi mata sipit tanpa menggunakan scote tape dan bulu mata palsu untuk rias malam dilihat dari indikator lipatan kelopak mata pada sampel 1 dengan skor 1,0 berkategori

\begin{tabular}{|c|c|c|c|}
\hline Indikator & Sampel 1 & Sampel 2 & Sampel 3 \\
\hline $\begin{array}{l}\text { Kesan } \\
\text { Panjang } \\
\text { Mata }\end{array}$ & $\begin{array}{l}\text { Panjang } \\
\text { mata } \\
\text { bertambah }\end{array}$ & $\begin{array}{l}\text { Panjang } \\
\text { mata } \\
\text { sangat } \\
\text { bertambah }\end{array}$ & $\begin{array}{l}\text { Panjang } \\
\text { mata } \\
\text { sangat } \\
\text { bertambah }\end{array}$ \\
\hline Rata-rata & \multicolumn{3}{|c|}{$\begin{array}{c}3,67=\text { Panjang mata terlihat sangat } \\
\text { bertambah }\end{array}$} \\
\hline $\begin{array}{l}\text { Kesan } \\
\text { Lebar } \\
\text { Mata }\end{array}$ & $\begin{array}{l}\text { Lebar mata } \\
\text { bertambah }\end{array}$ & $\begin{array}{l}\text { Lebar mata } \\
\text { bertambah }\end{array}$ & $\begin{array}{l}\text { Lebar mata } \\
\text { bertambah }\end{array}$ \\
\hline Rata-rata & \multicolumn{3}{|c|}{ 3,33=Lebar mata terlihat bertambah } \\
\hline $\begin{array}{l}\text { Lipatan } \\
\text { Kelopak } \\
\text { Mata }\end{array}$ & $\begin{array}{l}\text { Lipatan } \\
\text { kelompak } \\
\text { mata } \\
\text { terlihat }\end{array}$ & $\begin{array}{l}\text { Lipatan } \\
\text { kelopak } \\
\text { mata } \\
\text { sangat } \\
\text { terlihat }\end{array}$ & $\begin{array}{l}\text { Lipatan } \\
\text { kelopak } \\
\text { mata } \\
\text { sangat } \\
\text { terlihat }\end{array}$ \\
\hline Rata-rata & \multicolumn{3}{|c|}{$\begin{array}{c}\text { 3,67 }=\text { Lipatan Kelopak Mata sangat } \\
\text { terlihat }\end{array}$} \\
\hline
\end{tabular}

lipatan kelopak mata tetap, sampel 2 dengan skor 2,0 berkategori lipatan kelopak mata sedikit terlihat dan sampel 3 dengan skor 2,0 berkategori lipatan kelopak mata sedikit terlihat. Skor rata-rata keseluruhan yaitu 1,67 yang berarti lipatan kelopak mata sedikit terlihat dibandingkan dari bentuk awal.

Untuk lebih jelasnya tingkat hasil penerapan penerapan teknik ombre dipadu cat eyes terhadap koreksi mata sipit tanpa menggunakan scote tape dan bulu mata palsu untuk rias wajah malam hari dapat dilihat dengan grafik dibawah ini:

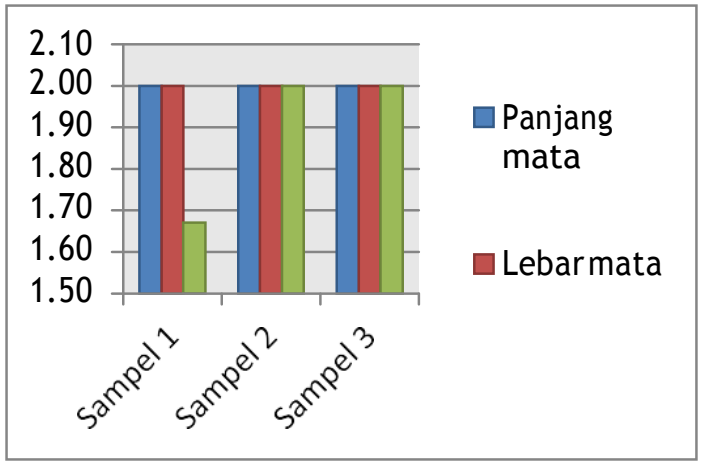

Gambar 1. Histogram Rata-rata Hasil Penerapan pada kelompok $\left(\mathrm{X}_{1}\right)$

2. Deskripsi Hasil Penerapan teknik ombre dipadu cat eyes terhadap koreksi mata sipit dengan menggunakan scote tape dan bulu mata palsu untuk rias malam pada Kelompok Eksperimen $\left(\mathrm{X}_{2}\right)$

\section{Tabel 2. Kelompok Eksperimen $\left(\mathbf{X}_{2}\right)$}

Dari tabel di atas diperoleh tingkat pencapaian keberhasilan yaitu:

a. Kesan Panjang Mata yang Terlihat

Penerapan teknik ombre dipadu cat eyes terhadap koreksi mata sipit dengan menggunakan scote tape dan bulu mata palsu untuk rias malampada dilihat dari indikator kesan panjang mata yang terlihat pada sampel 1 dengan skor 3,0 berkategori panjang mata bertambah, sampel 2 dengan skor 4.0, berkategori panjang mata sangat bertambah dan sampel 3 dengan skor 4,0 berkategori panjang mata sangat bertambah. Skor rata-rata keseluruhan yaitu 3,67 yang berarti kesan panjang mata yang terlihat sangat bertambah dari bentuk awal.

b. Kesan Lebar Mata yang Terlihat Penerapan teknik ombre dipadu cat eyes terhadap koreksi mata sipit dengan menggunakan scote tape dan bulu mata palsu untuk rias malam pada dilihat dari indikator kesan lebar mata yang terlihat pada sampel 1 dengan skor 3,0 berkategori lebar mata bertambah, sampel 2 dengan skor 2,0 berkategori lebar mata bertambah dan sampel 3 dengan skor 4,0 berkategori lebar mata sangat bertambah. Skor rata-rata keseluruhan yaitu 3,33 yang berarti kesan lebar mata yang terlihat bertambah dari bentuk awal.

c. Lipatan Kelopak Mata. 
Penerapan teknik ombre dipadu cat eyes terhadap koreksi mata sipit tanpa menggunakan scote tape dan bulu mata palsu untuk rias malam pada dilihat dari indikator lipatan kelopak mata pada sampel 1 dengan skor 3,0 berkategori lipatan kelopak mata terlihat, sampel 2 dengan skor 4,0 berkategori lipatan kelopak mata sangat terlihat dan sampel 3 dengan skor 4,0 berkategori lipatan kelopak

Test of Homogeneity of Variances

Skor

\begin{tabular}{|c|c|c|c|}
\hline tatistic & $\mathrm{df1}$ & $\mathrm{df} 2$ & Sig. \\
\hline 5.534 & 1 & 16 & .127 \\
\hline
\end{tabular}

mata sangat terlihat. Skor rata-rata keseluruhan yaitu 3,67 yang berarti lipatan kelopak mata sedikit sangat terlihat dibandingkan dari bentuk awal.

Untuk lebih jelasnya tingkat hasil $\mathrm{X}_{2}$ dapat dilihat dengan grafik dibawah ini:

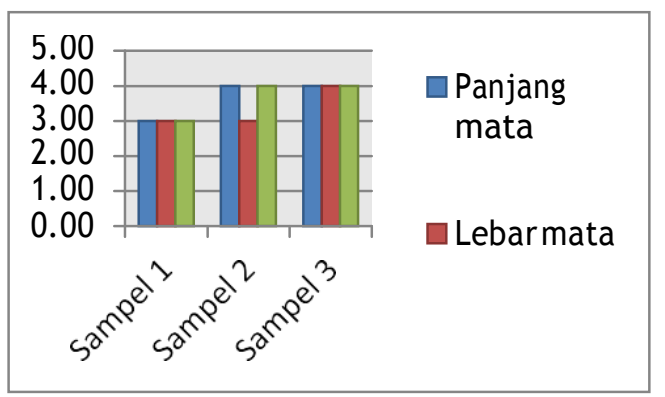

Gambar 2. Histogram Rata-rata Hasil Penerapan pada Kelompok Eksperimen $\left(\mathbf{X}_{2}\right)$

\section{A.Uji Persyaratan Analisis}

\section{Uji Normalitas}

\section{Tabel 3 Uji Normalitas}

Dari tabel di atas dapat dilihat bahwa skor signifikan probabilitas susunan data $X_{1}$ sebesar 0,316, susunan data X2sebesar 0.270 , karena nilai Asymp. Sig (2-tailed) lebih besar dari 5\% atau 0.05 maka dinyatakan bahwa susunan kedua kelompok data berdistribusi data normal.

\section{Uji Homogenitas}

\section{Tabel 4. Uji Homogenitas Pada Ketiga Kelompok}

Dari data di atas dapat diketahui bahwa harga Levene Statistic menunjukkan nilai signifikansi dengan skor 0.127, angka ini lebih besar dari signifikan $a$ (alpha) 0,05. Dengan demikian dapat disimpulkan bahwa kedua kelompok data memiliki varian yang homogen.

\section{B.Pengujian Hipotesis}

Hasil X1 dan X2

Tabel 5. Hasil Analisis Paired Sampel t Test

One-Sample Kolmogorov-Smirnov Test

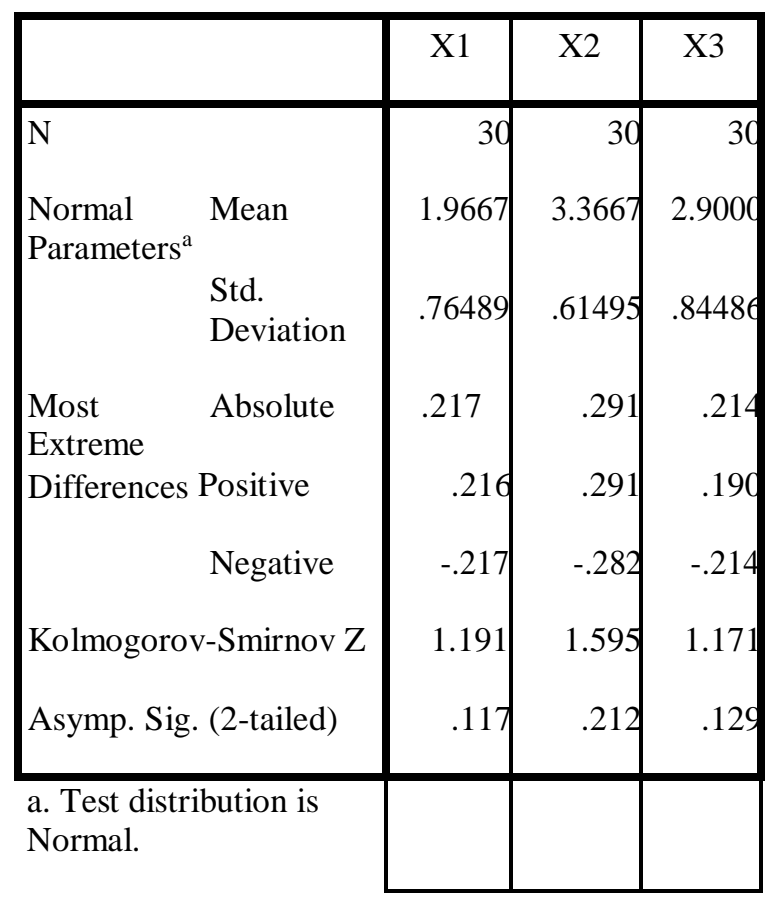


Data di atas menunjukkan bahwa nilai $\mathrm{t}$ hitung adalah sebesar (7.721), sedangkan nilai $t$ tabel untuk ketentuan df 7 pada taraf signifikansi 5\% adalah sebesar (1.895). Dengan demikian harga $t$ hitung $>t$ tabel $(7.721>1.895)$ hal ini membuktikan bahwa hipotesis yang berbunyi "Terdapat pengaruh yang signifikan pada penerapan teknik ombre dipadu cat eyes terhadap hasil koreksi mata sipit untuk rias malam" diterima pada taraf signifikansi $95 \%$. Sedangkan rata-rata hasil pada kelompok penerapan teknik ombredipadu cat eyes terhadap koreksi mata sipit dengan menggunakan scote tape dan bulu mata palsu untuk rias malam pada kelompok eksperimen memiliki rata-rata skor lebih tinggi, kelompok $\mathrm{X}_{1}$ memiliki rata-rata skor hasil rias wajah 1.875 sedangkan kelompok $\mathrm{X}_{2}$ memiliki rata-raata skor hasil rias wajah 3.625. Pembuktian dapat dilihat pada Tabel 6 berikut ini:

\section{Tabel 6. Hasil Perbedaan Skor Rata-rata Kedua Kelompok Sampel}

Paired Samples Test

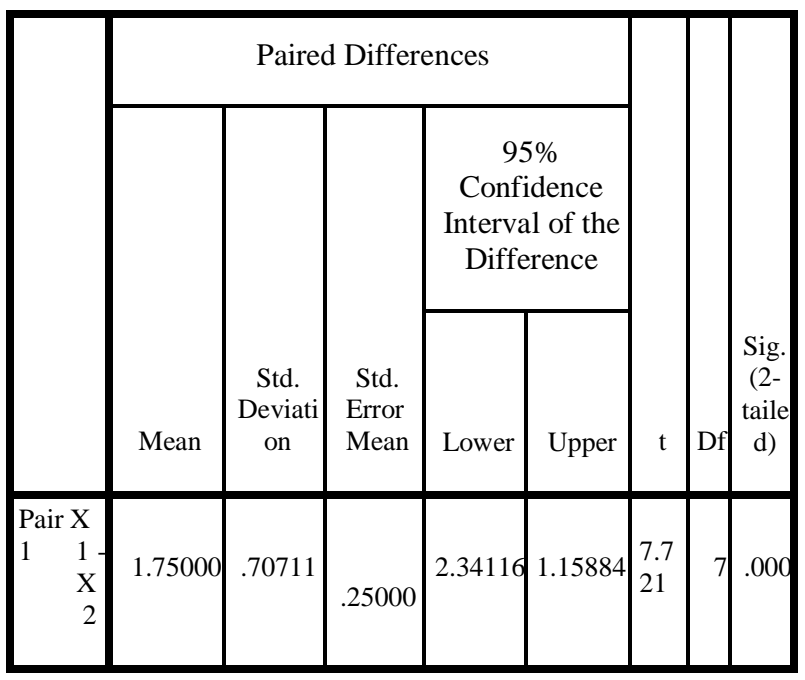

\section{B.P embahasan}

1. Penerapan teknik ombre dipadu cat eyes terhadap koreksi mata sipit tanpa menggunakan scote tape dan bulu mata palsu untuk rias malam.
Deskripsi data penelitian pada indikator kesan panjang mata yang terlihat memiliki skor rata-rata keseluruhan yaitu 2,0. Pada indikator kesan lebar mata yang terlihat memiliki skor rata-rata 2,0 sedangkan pada indikator lipatan kelopak mata skor rata-rata keseluruhan yaitu 1,67 yang berarti lipatan kelopak mata sedikit terlihat dibandingkan dari bentuk awal. Hasil penelitian ini menguatkan teori yang dikemukakan Gusnaldi (2006:32) menjelaskan bahwa

Paired Samples Statistics

\begin{tabular}{|c|c|c|c|c|}
\hline & Mean & $\mathrm{N}$ & $\begin{array}{c}\text { Std. } \\
\text { Deviation }\end{array}$ & $\begin{array}{l}\text { Std. Error } \\
\text { Mean }\end{array}$ \\
\hline Pair $1 \quad \mathrm{X} 1$ & 1.875 & 8 & .35355 & .12500 \\
\hline $\mathrm{X} 2$ & 3.625 & 8 & .51755 & .18298 \\
\hline
\end{tabular}

2. Penerapan teknik ombre dipadu cat eyes terhadap koreksi mata sipit menggunakan scote tape dan bulu mata palsu untuk rias malam

Hasil penelitian yang dapat dikemukakan untuk penerapan teknik ombre dipadu cat eyes terhadap koreksi mata sipit dengan menggunakan scote tape dan bulu mata palsu untuk rias malam dilihat dari indikator kesan panjang mata yang diproleh skor rata-rata keseluruhan yaitu 3,67 yang berarti kesan panjang mata yang terlihat sangat bertambah dari bentuk awal, skor rata-rata 3,33 dan skor rata-rata keseluruhan yaitu 3,67 yang berarti lipatan kelopak mata sedikit sangat terlihat dibandingkan dari bentuk awal.

Dengan demikian teknik ombre dan cat eyes yang dilakukan pada sampel tidak memberikan kesan maksimal pada indikator penilaian jika tidak dipadu dengan menggunakan bulu mata palsu dan scote tape. Maka penggunaan bulu mata palsu dan scote tape adalah solusi yang terbaik dalam mengesankan mata sipit memiliki tampilan yang lebih ideal dan indah pada rias wajah malam. 
3. Perbedaan hasil penerapan teknik ombre dipadu cat eyes terhadap koreksi mata sipit tanpa penggunaan scote tape dan bulu mata palsu dengan menggunakan scote tape dan bulu mata palsu untuk rias malam.

Berdasarkan hasil penellitian yang telah dilakukan diketahui bahwa hipotesis yang berbunyi Terdapat pengaruh yang signifikan pada penerapan teknik ombre dipadu cat eyes terhadap hasil koreksi mata sipit untuk rias malam" diterima pada taraf signifikansi 95\%. Hal ini berarti bahwa dari dua bentuk perlakuan penerapan teknik ombre dipadu cat eyes yang dilakukan yakni tanpa scote tape dan cat eyes dan dengan scote tape dan cat eyes terbukti terdapat perbedaan hasil yang nyata terlihat.

Sedangkan rata-rata hasil pada kelompok penerapan teknik ombre dipadu cat eyes terhadap koreksi mata sipit dengan menggunakan scote tape dan bulu mata palsu untuk rias malam pada kelompok eksperimen memiliki rata-rata skor lebih tinggi, kelompok X1 memiliki rata-rata skor hasil rias wajah 1.875 sedangkan kelompok X2 memiliki rata-rata skor hasil rias wajah 3.625. Kelompok eksperimen memiliki hasil rias wajah pada indikator kesan panjang mata, kesan lebar mata dan lipatan mata yang memiliki kategori yang jauh lebih baik dari kelompok kontrol.

Hasil penelitian ini merekomendasikan bahwa dengan teknik ombre dan cat eyes dapat memberikan kesan yang lebih ideal pada kecantikan mata sipit untuk rias malam. Namun teknik penambahan scote tape dan bulu mata palsu dapat efektif meningkatkan hasil rias wajah lebih baik. Dengan demikian maka disarankan untuk menggunakan scote tape dan bulu mata palsu untuk rias mata sipit.

\section{PENUTUP}

\section{Simpulan}

Berdasarkan hasil penelitian maka dapat disimpulkan sebagai berikut :

1. Penerapan teknik ombre dipadu cat eyes terhadap koreksi mata sipit tanpa menggunakan scote tape dan bulu mata palsu untuk rias malam kurang menunjukkan hasil yang kurang maksimal, rata-rata hasil hanya pada kategori kesan panjang mata dan kesan lebar mata yang sedikit bertambah dan lipatan kelopak mata yang sedikit terlihat. Pada kelompok X1 memiliki rata-rata skor hasil rias wajah 1.875.

2. Penerapan teknik ombre dipadu cat eyes terhadap koreksi mata sipit dengan menggunakan scote tape dan bulu mata palsu untuk rias malam menunjukkan hasil yang sangat maksimal, rata-rata hasil penelitian pada kategori kesan panjang mata dan kesan lebar mata yang sangat bertambah dan lipatan kelopak mata yang sangat terlihat kelompok $\mathrm{X} 2$ memiliki rata-rata skor hasil rias wajah 3.625 .

3. Hipotesis yang berbunyi "terdapat pengaruh yang signifikan pada penerapan teknik ombre dipadu cat eyes terhadap hasil koreksi mata sipit untuk rias malam" diterima pada taraf signifikansi $95 \%$. Hal ini berarti bahwa dari dua bentuk perlakuan penerapan teknik ombre dipadu cat eyes yang dilakukan yakni tanpa scote tape dan cat eyes dan dengan scote tape dan cat eyes terbukti terdapat perbedaan hasil yang nyata terlihat.

\section{Saran}

1. Kepada Prodi Pendidikan Tata rias dan kecantikan Fakultas Pariwisata dan Perhotelan, hasil dari penelitian ini dapat menjadi masukan sebagai referensi bahan perkuliahan pada mata kuliah rias wajah dengan menggunakan scote tape dan bulu mata palsu dapat memaksimalkan hasil rias wajah malam pada mata sipit.

2. Kepada mahasiswa tata rias dan kecantikan yang melakukan rias wajah malam khususnya pada mata sipit dapat disarrankan untuk menggunakan teknik ombre dipadu cat eyes dan menggunakan tambahan bulu mata plasu dan scote tape.

3. Kepada masyarakat yang memiliki masalah mata sipit untuk dapat mendapatkan hasil rias wajah mata yang maksimal maka dapat menggunakan rias wajah dengan menggunakan teknik ombre dan cat eyes dengan dipadu bulu mata palsu dan scote tape.

4. Penelitian ini bermanfaat untuk peneliti sendiri dan para praktisi atau pihak yang berkecimpung di bidang kecantikan khususnya rias wajah dapat menerapkan teknik ombre dan cat eyes dengan menggunakan tambahan scote tape dan bulu mata palsu. 


\section{DAFTAR PUSTAKA}

Andiyanto, 2003. The Make Over Rahasia Rias

Wajah Sempurna. Jakarta : Gramedia Pustaka Utama.

Gusnaldi,2003. The Power of Makeup. Jakarta : PT. Gramedia Pustaka Utama.

Gusnaldi, 2009. Instan Makeup.Jakarta : PT. Gramedia Pustaka Utama.

Kusumawardhani Ren, 2008. Miracle Makeup. Jakarta: Gramedia.

Ovyntarima, Ritinia, 2014."Pengaruh Aplikasi Teknik Ombre Dipadu Cat Eyes Terhadap Hasil Riasan Koreksi Mata Sipit Untuk

Permadi, Bimo, 2014. Panduan Simpel Untuk Merawat Kecantikan Anda. Jakarta : Gramedia Widiasarana Indonesia.2014.

Rahmiati, dkk, 2013. Merias Diri. Padang: UNP Press.

Octaviyanti. Make Over,2013. Yogyakarta : Pustaka Baru Press. 2015.

Suryawan, Debbi S, 2006. Beauty Expose. Jakarta: Gramedia Pustaka Utama. 2006. 